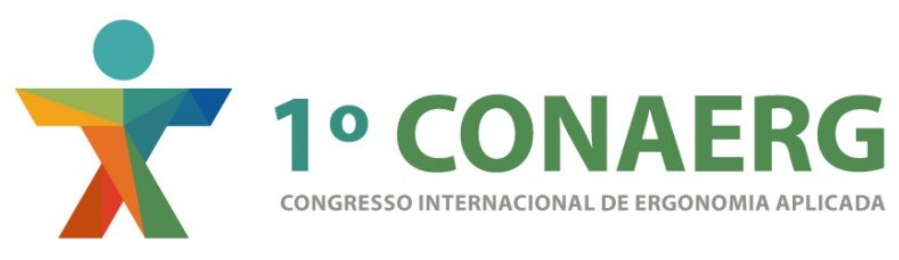

\title{
O HOME OFFICE E A ERGONOMIA NAS CONDIÇÕES DE TRABALHO E SAÚDE DE ARQUITETOS E ENGENHEIROS
}

\author{
Jose Alberto Barroso Castañon (1); \\ Tairine Cristine Bertola Cruz (2); \\ Juliana Lodi Carvalho (3); \\ Guilherme Nogueira Ragone (4). \\ (1) Universidade Federal de Juiz de Fora, D.Sc. Engenharia de Transportes \\ e-mail: jose.castanon@ufjf.edu.br \\ (2) Universidade Federal de Juiz de Fora, Mestranda em Ambiente Construído \\ e-mail: tbertolacruz@hotmail.com \\ (3) Universidade Federal de Juiz de Fora, Mestranda em Ambiente Construído \\ e-mail: julodicarvalho@gmail.com \\ (4) Universidade Federal de Juiz de Fora, Mestrando em Ambiente Construído \\ e-mail: guilhermeragone@hotmail.com

\begin{abstract}
RESUMO
Com a criação da comunicação eletrônica, surgiu o teletrabalho ou trabalho à distância. Um arranjo bastante comum neste sistema é o Home Office, trabalho no domicílio. O presente artigo buscou avaliar a intervenção ergonomizadora no trabalho de 65 profissionais autônomos, especificamente arquitetos e engenheiros que projetam neste ambiente. Os participantes responderam a um questionário com perguntas sobre aspectos psicossociais e sobre a infraestrutura do local. Também foi feita uma análise sobre a saúde física do corpo. Observou-se como principais vantagens apontadas a flexibilidade e a redução de tempo com transporte. Nas desvantagens, verificou-se o isolamento profissional e interrupções no trabalho.
\end{abstract}

Palavras chave: Home Office, ergonomia, saúde.

\section{ABSTRACT}

The telecommuting or teleworking is associated with the creation of electronic communication. $A$ common arrangement in this working system is the Home Office, work made from home. This paper aims to evaluate the ergonomic intervention in the work of 65 independent professionals, especially architects and engineers who design in this environment. The participants answered a questionnaire with questions about psychosocial aspects and the infrastructure of the place. There was also an analysis of the physical health of the body. The main advantages reported relate about the flexibility and reduce of the time spent with transport. In the disadvantages, they pointed professional isolation and work stoppages.

Keywords: Home Office, ergonomics, health. 


\section{INTRODUÇÃO}

\section{A concepção do Home Office}

A partir da segunda metade do século $X X$, com o avanço da globalização e o surgimento das novas tecnologias, inicia-se um novo período no capitalismo denominado pós-moderno ou pós-industrial. A forma de comunicação e interação desta sociedade passa por uma grande revolução e, consequentemente, as relações de trabalho também evoluem em conjunto com as mudanças históricas, políticas e sociais (KUMAR, 2006). Rafalski e Andrade (2015) apontam como exemplos dessas modificações, a flexibilização da produção, a terceirização da mão de obra, a produção just-in-time e a maior valorização e preocupação com o capital humano e psicológico no ambiente de trabalho.

Ao longo dos anos, os trabalhadores e as organizações foram se adaptando aos novos modelos de desenvolvimento. Segundo Oliveira (1996), a revolução cibernética deu origem a uma nova modalidade de trabalho, "o trabalho à distância", aquele que pode ser realizado em qualquer lugar. Kumar (2006) em seu livro "Da sociedade pós-industrial à pós-moderna: Novas teorias sobre o mundo contemporâneo" cita que a sociedade industrial evoluiu para uma sociedade de serviços com crescimento de oportunidades e empregos para profissionais liberais. Em seguida, referencia o pensamento de John Naisbitt em Megatendências (1984): "A tecnologia do computador é para a era da informação o que a mecanização foi para a Revolução Industrial".

Para Castells (1999), o desenvolvimento da comunicação eletrônica e dos sistemas de informação são fatores que possibilitaram a dissociação entre a proximidade geográfica e o desempenho de funções rotineiras como trabalho, compras, entretenimento e educação. Em 1999, o autor já apontava em "A sociedade em rede" uma tendência cada vez maior de as pessoas trabalharem e administrarem serviços em suas casas.

Alguns anos antes, Nilles (1976) publicou nos Estados Unidos o livro "The telecommunications-transportation tradeoff: options for tomorrow" onde o termo telecommuting, traduzido como teletrabalho, foi utilizado pela primeira vez como referência à possibilidade de se eliminar o trajeto casa-trabalho por meio dos recursos oferecidos pelas Tecnologias de Comunicação e Informação (Information and Communication Technologies ICTs) (NILLES, 1976 apud COSTA, 2003).

Segundo Qvortup, citado por Castells (1999), existem três categorias de teletrabalhadores: os substituidores, que substituem o serviço efetuado no ambiente de trabalho tradicional pelo serviço em casa; os autônomos, que trabalham on-line em suas casas; e os complementadores, que trazem para casa trabalho complementar do escritório convencional.

Dentre as diferentes formas de organização do trabalho à distância, o Home Office, também conhecido pela sigla SOHO - Small Office and Home Office, é considerado como um dos arranjos mais comuns (SANTOS, 2012). Autores como Ellison (1999) e Lim \& Teo (2000) definem que a modalidade de trabalho Home Office se caracteriza pela inserção do trabalho em um espaço sem tamanho ou propriedades definidas, destinado somente a atividades profissionais e localizado na residência do trabalhador, sendo facultativo o uso de tecnologias (ELLISON, 1999; LIM \& TEO, 2000 apud RAFALSKI e ANDRADE, 2015).

Para Brik e Brik (2013) existem três possíveis configurações de Home Office: o trabalhador pode ser funcionário de uma empresa, neste caso tem-se o teletrabalho; o trabalhador pode executar projetos independentes, neste caso ele é um freelancer; e o trabalhador pode se tornar o empresário de uma home based, empresa com sede em sua residência.

Segundo Oliveira (1996) o aumento da procura por trabalhos flexíveis está relacionado principalmente à inserção da mulher no mercado de trabalho e à ocorrência de crises econômicas que desencadeiam elevação nos níveis de desemprego. Costa (2003) destaca que antes da Revolução Industrial era comum trabalhar-se em casa. No entanto, as formas 
tradicionais deste modo de trabalho diferenciam-se bastante do fenômeno atual em virtude das ICTs, que permitem a virtualização do espaço e do tempo, fazendo com que uma atividade possa ser feita em qualquer hora e lugar.

\section{O Home Office e a Ergonomia}

De acordo com a Associação Internacional de Ergonomia (International Ergonomics Association - IEA) a Ergonomia é uma disciplina científica que busca o entendimento das interações entre os seres humanos e outros elementos ou sistemas. Através de seus estudos, os ergonomistas contribuem para o planejamento, projeto e a avaliação de tarefas, postos de trabalhos, produtos, ambientes e sistemas, de modo a torná-los mais compatíveis com as necessidades, habilidades e limitações humanas (ABERGO, 2016).

Segundo Laville (1977) a ergonomia nasceu a partir de necessidades práticas e pode ser definida como o conjunto de conhecimentos a respeito do desempenho do homem em atividade, a fim de melhorar a concepção dos ambientes, instrumentos, máquinas e sistemas de produção. Pode ainda ser considerada uma área interdisciplinar que recorre a conhecimentos científicos diversos, como a Fisiologia, a Psicologia do Trabalho e a Antropometria, para estabelecer suas normas e leis de aplicação.

Avancini e Ferreira (2003) destacam que o objetivo da Ergonomia é tornar o trabalho das pessoas mais seguro, confortável e produtivo. Para Panero e Zelnik (2015), a interface entre o usuário e o ambiente projetado deve garantir conforto, segurança e uma vivência agradável. Desta forma, as dimensões corporais refletem, por exemplo, na configuração da altura de superfícies de trabalho, nos espaços livres para cadeiras, nas alturas de prateleiras e nas larguras de corredores.

A ciência da Ergonomia movimenta-se de forma similar à dinâmica do trabalho e ao progresso dos recursos tecnológicos. O homem vive e trabalha em ambientes que podem ser caracterizados por meio de medidas físicas, como por exemplo, as condições térmicas, sonoras, luminosas e vibratórias. Para garantir a integridade do organismo humano, a Ergonomia aplica-se na determinação de limites, níveis perigosos e de características ótimas para os meios de trabalho, desenvolvendo pesquisas e estudos a fim de definir regras aplicáveis à transformação destes (PANERO e ZELNIK, 2015).

O presente artigo buscou avaliar a intervenção ergonomizadora sobre o trabalho de arquitetos e engenheiros autônomos que projetam no ambiente do Home Office, entendendo-se que trabalhar em domicílio apresenta algumas particularidades relativas às questões psicossociais diferentes das situações relacionadas ao trabalho convencional.

\section{DELINEAMENTO DA PESQUISA}

\section{O estudo}

Para fins de definição, neste estudo trabalhar em Home Office se caracteriza por desempenhar atividades profissionais autônomas no mesmo ambiente em que se reside. $O$ interesse principal foi explorar a atuação de profissionais da construção civil, especificamente arquitetos e engenheiros, que utilizam o Home Office nas atividades de trabalho.

De acordo com Laville (1977), os principais dados ergonômicos que compõem a situação de trabalho são: o meio ambiente físico e características sobre a duração, os horários e as pausas, que devem ser analisados de forma integrada pois funcionam em conjunto. Além disso, praticamente todas as tarefas de trabalho possuem, além da atividade física, a atividade mental que varia em sua importância e complexidade.

Neste seguimento, as principais questões abordadas dizem respeito a: aspectos psicossociais, como o isolamento do indivíduo, a organização e disciplina, a carga de 
horário exercida e as relações interpessoais na família; a infraestrutura do local de trabalho, questões relacionadas ao conforto e adaptações do ambiente; e uma análise sobre a saúde física do corpo.

\section{Justificativa e aplicabilidade}

De acordo com o Censo de 2010, divulgado pelo IBGE - Instituto Brasileiro de Geografia e Estatística, cerca de 20 milhões de brasileiros trabalham em seu domicílio. Como destacam Rafalski e Andrade (2015), no Brasil os estudos sobre essa temática ainda são bastante incipientes e se concentram em dissertações, teses e trabalhos publicados em anais de eventos científicos. Tendo em vista esta lacuna, esta pesquisa se justifica na contribuição para o conhecimento acerca deste crescente modo de configuração do trabalho.

\section{Objetivos}

- Geral

- Explorar e investigar as implicações sociais e psicológicas dos aspectos de trabalho que norteiam o desempenho de arquitetos e engenheiros no modelo de trabalho em Home Office.

\section{- Específicos}

- Observar a frequência (horas/dias/anos) do trabalho em Home Office;

- Verificar as vantagens e desvantagens observadas pelos entrevistados quanto ao trabalho em casa;

- Estimar o nível de preocupação dos entrevistados em ajustar o ambiente de trabalho;

- Estimar a predominância de incômodos/desconforto/dor, considerando diferentes regiões do corpo, após as atividades de trabalho.

\section{MÉTODOS E TÉCNICAS}

\section{Instrumentos e procedimentos}

Sobre o ponto de vista de seus objetivos, a presente pesquisa pode ser classificada de cunho descritivo e caráter exploratório, pois tratou-se de um levantamento para descrever as características observadas no comportamento de engenheiros e arquitetos usuários do Home Office. Na pesquisa descritiva, os dados são observados, analisados e interpretados através de questionários, formulários e entrevistas. O caráter exploratório tem como finalidade proporcionar mais informações sobre o assunto investigado com vista de torná-lo mais explícito. Para a análise das informações e dos dados levantados, utilizou-se de recursos e técnicas estatísticas, conferindo aos resultados uma abordagem quantitativa (PRODANOV e FREITAS, 2013).

Para a coleta das informações, optou-se por elaborar um questionário on-line, através da plataforma Googleforms. A escolha desta deu-se em função de uma maior abrangência para o estudo. O questionário foi realizado seguindo as recomendações de Nogueira (2012). Inicialmente, foi realizado um teste com a aplicação de um questionário piloto impresso, o qual possibilitou um refinamento e melhorias para o questionário final. Neste questionário piloto houve a preocupação de se cronometrar o tempo de respostas e disponibilizou-se ao usuário um espaço aberto para opinar sobre eventuais dúvidas e questionamentos. Acredita-se que esta fase foi de grande importância para o desempenho do questionário final.

O recrutamento dos participantes foi realizado a partir de convites de divulgação via e-mail e através de redes sociais. O tempo de coleta de dados correspondeu a duas semanas, entre os períodos dos dias 06 ao dia 20 de Junho de 2016. Após o encerramento da coleta de 
dados, procedeu-se a análise das respostas e a interpretação dos resultados obtidos com a literatura estudada.

\section{O questionário}

O questionário proposto constituiu-se de três partes. A primeira continha perguntas com respostas de múltipla escolha de forma a conhecer o usuário, sua profissão e aspectos sobre o nível de produtividade no Home Office.

$\mathrm{Na}$ segunda parte, em um primeiro momento, os usuários especificaram seu nível de concordância sobre algumas afirmações acerca da infraestrutura e do conforto no ambiente de trabalho. Para isso, utilizou-se a escala Likert (Figura 1), um tipo de escala de resposta psicométrica usada habitualmente em questionários quando se têm uma pesquisa de opinião (NOGUEIRA, 2012). Em um segundo momento, os usuários classificaram as principais vantagens e desvantagens percebidas no Home Office.

Figura 1 - Escala Likert de avaliação

\begin{tabular}{|c|c|c|c|c|}
\hline \multicolumn{4}{|c|}{ Escala de Avaliação } \\
\hline $\begin{array}{c}\text { Concordo } \\
\text { plenamente }\end{array}$ & $\begin{array}{c}\text { Concordo } \\
\text { parcialmente }\end{array}$ & $\begin{array}{c}\text { Não concordo } \\
\text { nem discordo }\end{array}$ & $\begin{array}{c}\text { Discordo } \\
\text { parcialmente }\end{array}$ & $\begin{array}{c}\text { Discordo } \\
\text { plenamente }\end{array}$ \\
\hline
\end{tabular}

Fonte: elaborado pelos autores.

$\mathrm{Na}$ terceira e última parte, para especificar possíveis desconfortos físicos experimentados pelo usuário no ambiente do Home Office, após as atividades de trabalho, utilizou-se o mapa corporal proposto por Corllet e Manenica (1980). Foi aplicada uma escala de avaliação, adaptada por Duque (2006), onde o entrevistado definiu o local de dor, de acordo com a Figura 2, em três níveis distintos: muita dor, pouca dor ou nenhuma dor (Figura 3).

Figura 2: Mapa de regiões corporais utilizados na pesquisa

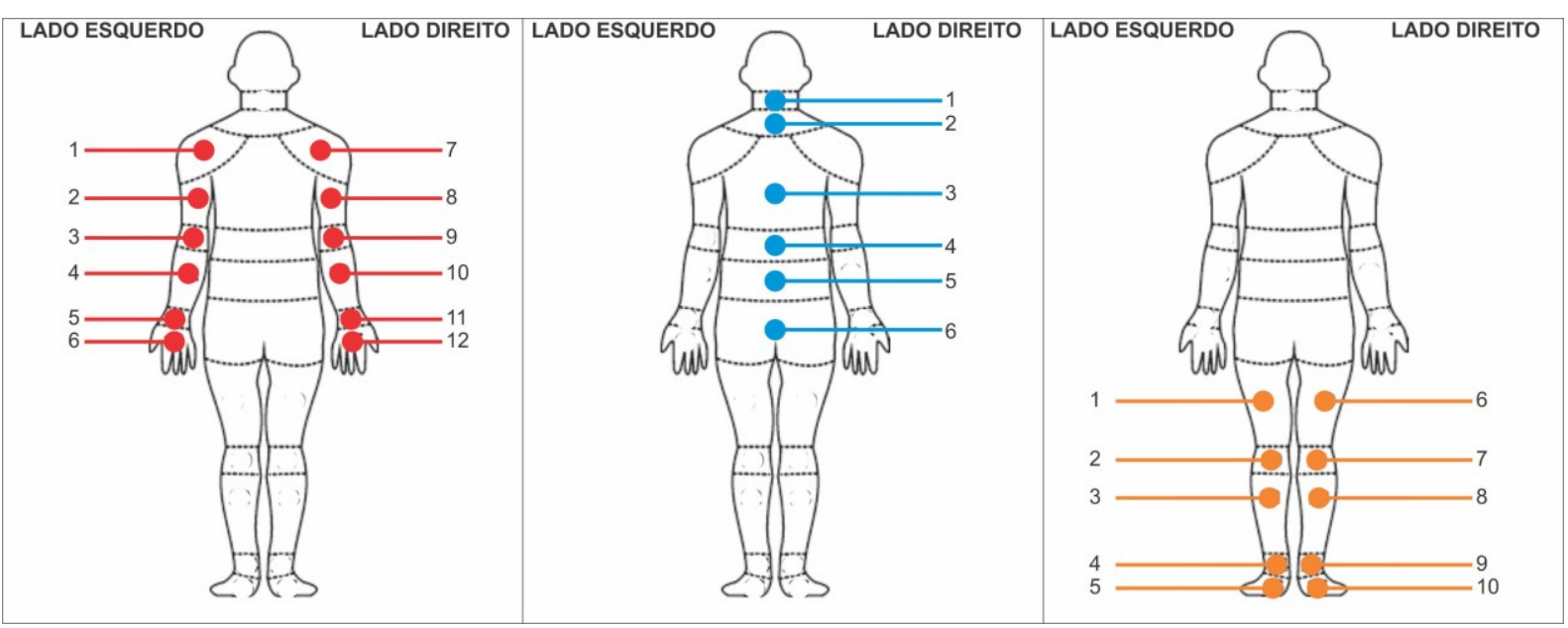

Fonte: Corlett e Manenica (1980), adaptado pelos autores em membros superiores, tronco e membros inferiores.

Figura 3: Escala de avaliação de dor

\begin{tabular}{|l|l|l|}
\hline \multicolumn{3}{|c|}{ Escala de Avaliação } \\
\hline Muita dor & Nenhuma dor & Pouca dor \\
\hline
\end{tabular}

Fonte: Duque (2006). 


\section{RESULTADOS E DISCUSSÃO}

\section{Os participantes}

Participaram deste estudo 65 profissionais atuantes no município de Juiz de Fora, Minas Gerais. Destes, 56,9 \% do sexo feminino com idades variando entre 21 e 59 anos. Quanto à profissão, observou-se mais de $80 \%$ arquitetos.

Quando perguntados sobre o tempo de utilização do Home Office, uma grande parcela dos entrevistados $(49,2 \%)$ atua neste tipo de trabalho entre 1 e 3 anos. Com relação à frequência, $41,5 \%$ revelaram trabalhar 5 vezes por semana e $18,5 \%$ mais de 5 dias por semana.

O momento do dia apontado como o mais produtivo foi o turno da manhã com $38,5 \%$. Já os turnos da tarde e da noite apresentaram $26,2 \%$ e $24,6 \%$ respectivamente. A madrugada obteve o menor índice, 10,8\%.

A ferramenta de trabalho mais utilizada foi o notebook com $87,7 \%$, seguido do desktop com $48,5 \%$ de uso.

\section{Infraestrutura do ambiente Home Office}

A grande maioria dos participantes demonstrou ter tido alguma preocupação em ajustar o ambiente de trabalho ( $40 \%$ concordaram parcialmente e $36,9 \%$ plenamente). As adaptações mais recorrentes foram com relação a melhorias na iluminação, mudanças de mesas e cadeiras e a adaptação de um ambiente exclusivo para o trabalho.

Segundo lida e Guimarães (2016), o projeto ergonômico do ambiente de trabalho visa melhorar a eficiência do serviço desempenhado, assegurando a saúde, segurança e satisfação do trabalhador. O dimensionamento correto desse local é uma etapa fundamental para um bom desempenho do serviço, permitindo que o trabalhador mantenha uma postura natural (não forçada) e realize movimentos harmônicos. Sobre os aspectos mencionados, as recomendações são de que a altura da mesa deve ser conjugada com a altura da cadeira. Se a mesa tiver uma altura fixa, a cadeira deve ter uma altura regulável e vice-versa. Ainda, a iluminação e as cores também são essenciais para o trabalho humano, já que grande parte das informações ambientais é captada pela visão. O correto planejamento da iluminação contribui para prevenir erros, aumentar a satisfação no trabalho e melhorar a produtividade.

Quanto à utilização do espaço de trabalho por outras pessoas, observou-se que $36,9 \%$ dos entrevistados discordaram totalmente desse uso e, em contrapartida, a mesma porcentagem concordou plenamente com o mesmo.

Em 2010, o SEBRAE - Serviço Brasileiro de Apoio às Micro e Pequenas Empresas disponibilizou um manual com recomendações para usuário do Home Office, destacando que o trabalho no domicílio exige muita motivação, disciplina e concentração para evitar distrações que possam levar à perda de produtividade. O trabalhador não pode, por exemplo, ser incomodado durante o seu horário de trabalho.

Dos entrevistados, 38,5\% concordaram parcialmente quanto à coordenação para início e fim dos trabalhos e outros $27,7 \%$ concordaram plenamente com essa afirmação. Quando questionados sobre trabalhar mais horas a fim de cumprir prazos, a grande maioria $(87,7 \%)$ concordou plenamente. Com relação às pausas durante o horário de trabalho, $44,6 \%$ concordam plenamente e $32,3 \%$ parcialmente.

Avancini e Ferreira (2003) definem que a carga de trabalho é o conjunto das demandas e exigências sobre o trabalhador. Quando esta ultrapassa o limite considerado saudável, o trabalhador entra no estado de fadiga, caracterizado por alterações no sistema nervoso, insônias, dores de cabeça e no estômago. Para evitar a fadiga e o estresse, são 
necessárias as pausas, trabalhar em um ambiente harmonioso, praticar atividades de lazer fora do trabalho e principalmente dormir satisfatoriamente.

Quando perguntados sobre as vantagens do Home Office, as opiniões mais levantadas foram sobre a flexibilidade $(89,4 \%)$, maior autonomia e liberdade $(81,8 \%)$ e não ter que procurar vagas e nem enfrentar trânsito com o deslocamento para o trabalho $(48,5 \%)$. Quanto às desvantagens, as questões mais abordadas foram as interrupções durante 0 horário de trabalho $(60,6 \%)$, dificuldade em separar vida profissional de vida pessoal $(54,5 \%)$ e o isolamento profissional e social $(53 \%)$.

Segundo Costa (2003), o trabalho em domicílio pode ser visto como a solução para problemas de aspectos sociais, organizacionais e individuais bastante complexos e diversos. No que se refere aos problemas sociais, a prática contribui na melhoria do trânsito, diminuição da poluição e do número de acidentes, além de permitir a inclusão de minorias no mercado de trabalho e a revitalização econômica de regiões fora dos grandes eixos de produção. A nível organizacional, colabora principalmente no corte de despesas com a infraestrutura de um escritório. Quanto ao indivíduo, as vantagens dizem respeito à possibilidade de equilibrar a vida familiar e o trabalho, economizar tempo com o deslocamento casa-escritório, a flexibilidade de horários, autonomia e redução de gastos com transporte e vestuário. $\mathrm{E}$ sobre as desvantagens, tem-se a questão do isolamento social e a possíveis limitações ao desenvolvimento da carreira.

\section{Análise da saúde física do corpo}

Os resultados obtidos na avaliação do desconforto corporal indicaram uma significativa predominância de desconforto/dor na região do tronco, que compreende o pescoço, as costas e a bacia (Gráfico 1).

\section{Gráfico 1: Estimativa do nível de dor na região do tronco}

\section{Região do tronco}

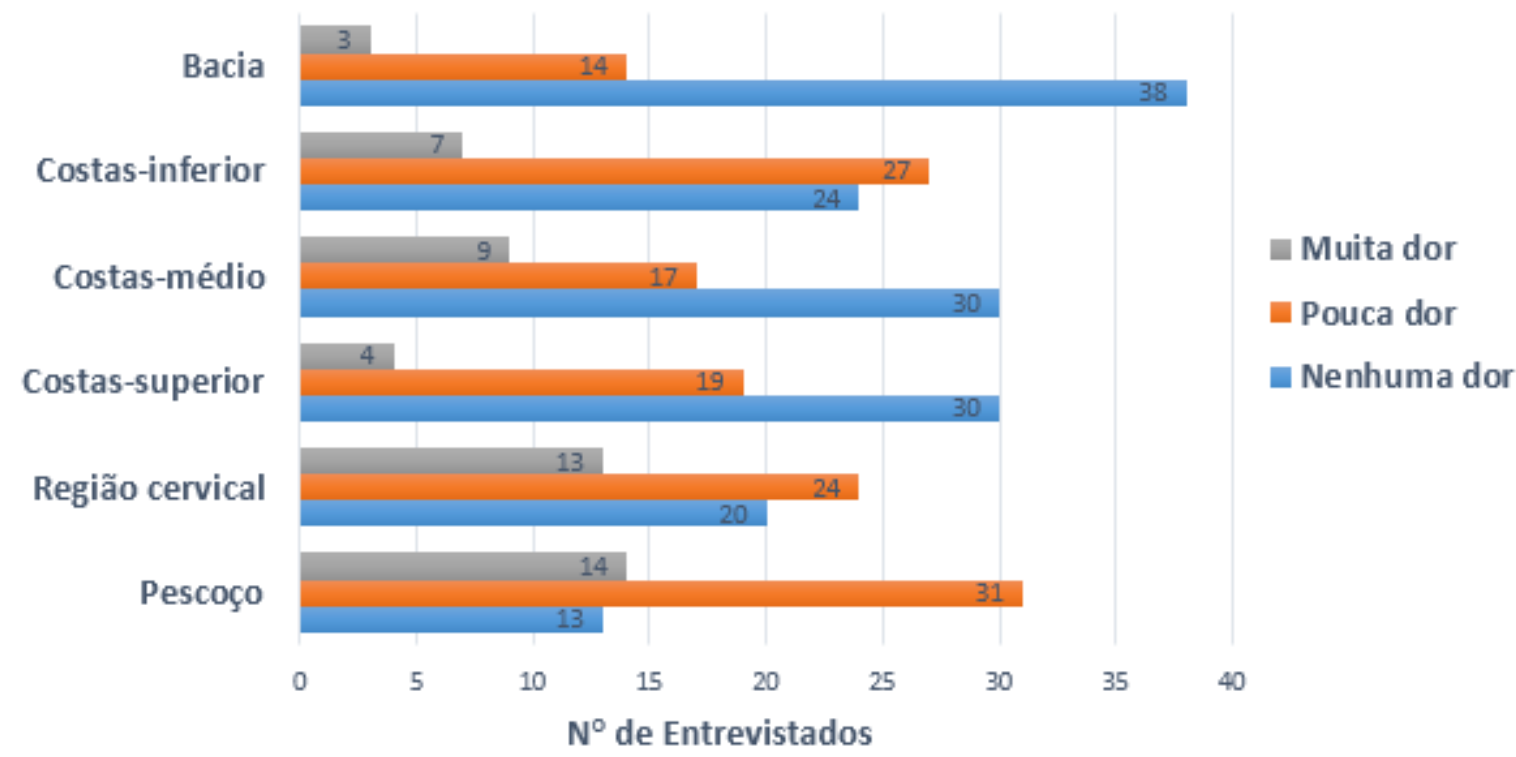

Fonte: elaborado pelos autores.

Em seguida, tem-se os membros superiores, especificamente os ombros, mãos e punhos (Gráficos 2 e 3). Observou-se que as dores relatadas são características do trabalho com computadores, predominante na população pesquisada. 
Gráfico 2: Estimativa do nível de dor nos membros superiores - lado direito

Membros Superiores

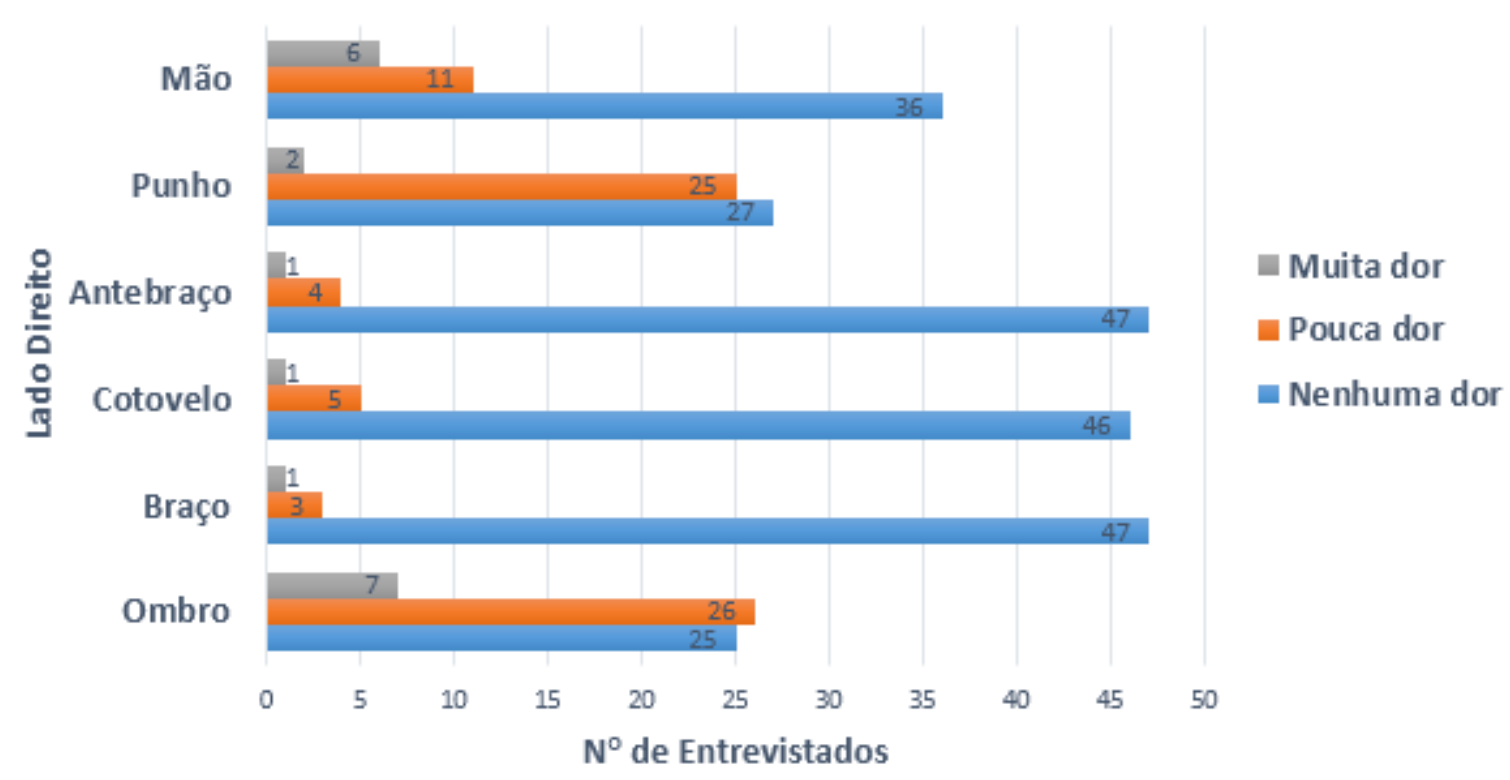

Fonte: elaborado pelos autores.

Gráfico 3: Estimativa do nível de dor nos membros superiores - lado esquerdo

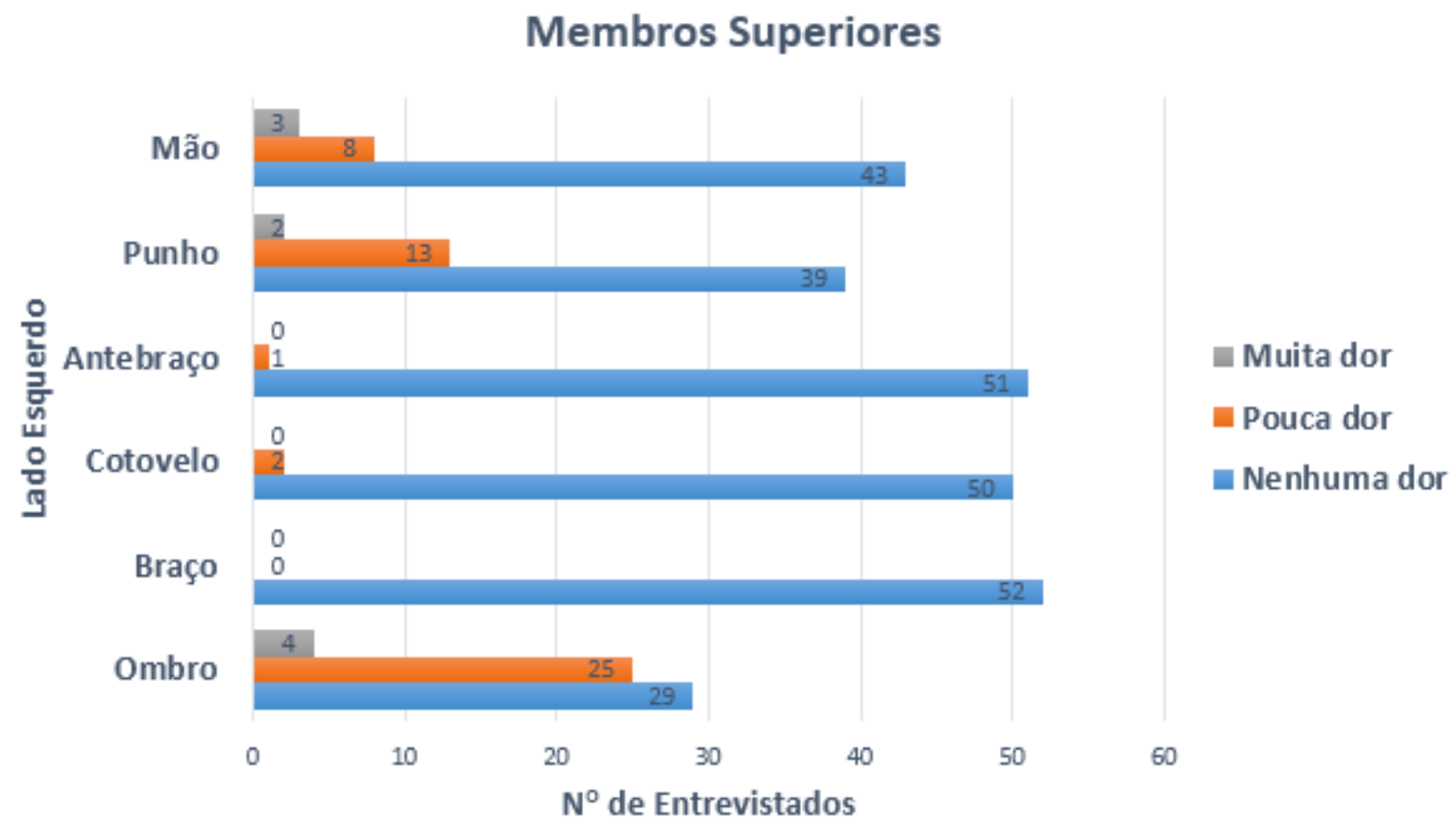

Fonte: elaborado pelos autores. 
Nos membros inferiores, observou-se pouca incidência de relatos de dor (Gráficos 4 e 5). As dores relatadas nessas áreas podem ser características do trabalhado de longa duração na posição sentado.

Gráfico 4: Estimativa do nível de dor nos membros inferiores - lado esquerdo Membros Inferiores

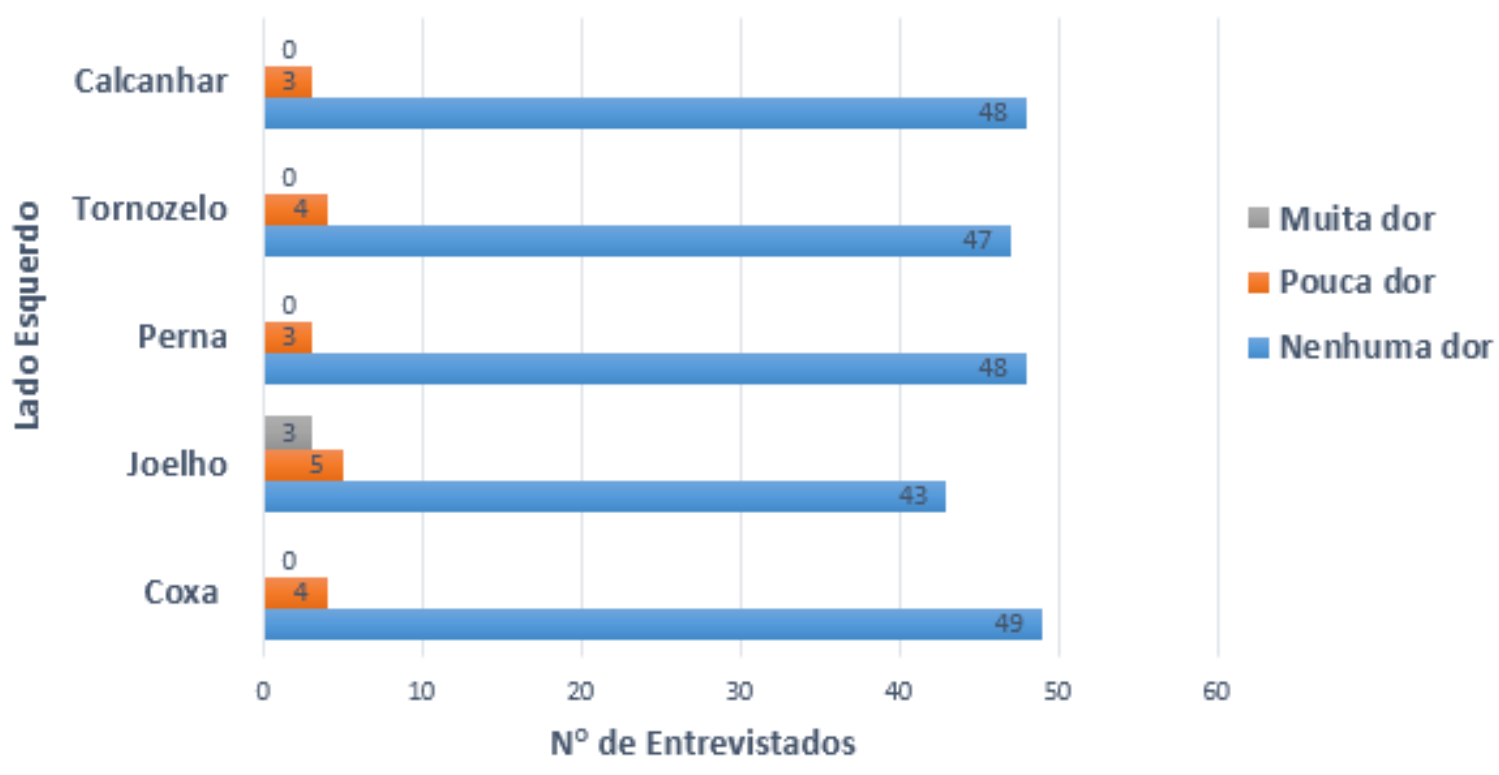

Fonte: elaborado pelos autores.

Gráfico 5: Estimativa do nível de dor nos membros inferiores - lado direito Membros Inferiores

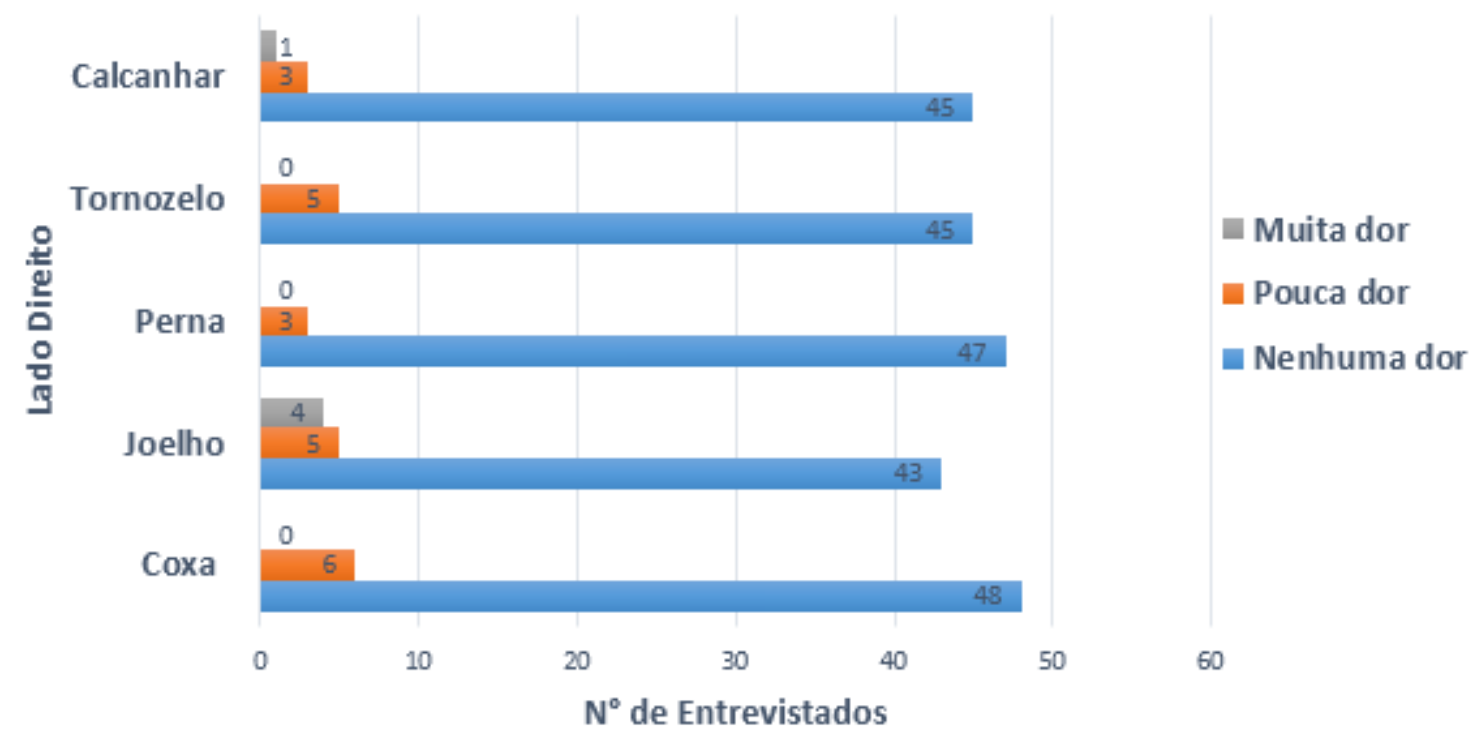

Fonte: elaborado pelos autores.

Segundo Avancini e Ferreira (2003), a postura também é um fator influenciador na fadiga. É necessário que o mobiliário seja adequado de forma a atenuar a força envolvida em uma determinada atividade. Laville (1977) aponta que a postura pode ser definida como a 
organização dos segmentos corporais no espaço, submetendo-se a características anatômicas e fisiológicas do corpo humano e mantendo estreito relacionamento com as atividades de trabalho. Além da fadiga muscular, os efeitos a longo prazo de uma postura desequilibrada são numerosos: sobrecarga impostas ao aparelho respiratório, formação de edemas, varizes e afecções nas articulações, artrose, bursite ou sinovite, deformação da coluna vertebral e/ou hérnias de disco.

Tanto a falta de exercícios, quanto o excesso de um determinado movimento podem causar circunstâncias desfavoráveis para a manutenção da boa saúde (IIDA e GUIMARÃES, 2016). De fato, observou-se que as regiões mais citadas condizem os esforços repetitivos envolvidos nas atividades do projetista: sentar, digitar e desenhar.

\section{CONSIDERAÇÕES FINAIS}

A sociedade pós-moderna viveu uma grande revolução tecnológica e o mundo do trabalho sofreu profundas transformações. Esse artigo teve como objetivo contribuir para o conhecimento sobre a temática do Home Office, mais especificamente, sobre a dinâmica da realização do trabalho em casa.

A pesquisa tratou de explorar as realidades cotidianas do trabalho domiciliar, investigando aspectos psicossociais, a infraestrutura do ambiente de trabalho e sobre a saúde física do corpo de arquitetos e engenheiros que projetam no ambiente do Home Office.

A fim de criar subsídios necessários para seu desenvolvimento, buscou-se apresentar a temática do Home Office com a construção do conceito fundamental de ergonomia, explorando o conhecimento que vem sendo construído sobre as realidades da combinação do trabalho no domicílio.

Segundo lida e Guimarães (2016), o planejamento do Home Office, é realizado em duas etapas: a escolha do arranjo físico e o dimensionamento, o primeiro de natureza qualitativa e o segundo quantitativo. Na escolha do arranjo físico, tem-se a definição dos equipamentos básicos de trabalho - mesa, bancada, cadeira, eletrônicos, - para o posicionamento adequado do trabalhador, que segundo Laville (1977), deve privilegiar as exigências visuais, de precisão de movimentos, de força a ser exercida, dos espaços aonde o operador atuará e seu ritmo de execução. Deve-se considerar também, o estabelecimento das prioridades das ações, sendo assim, as áreas mais importantes devem ser a mais próximas ao alcance operacional.

Embora à primeira vista, o trabalho no domicílio apresente vantagens, observou-se que, na prática, ocorre uma substituição dos problemas comumente encontrados em escritórios. Ao mesmo tempo que o Home Office pode proporcionar ao indivíduo uma oportunidade de maior integração com a família, flexibilidade e liberdade para o melhor aproveitamento do tempo de trabalho, assim como menor estresse com o trânsito, ele pode sofrer com as interrupções durante o horário de trabalho, dificuldade em separar vida profissional de vida pessoal, isolamento profissional e ainda problemas no corpo quando não há preocupações em ajustar o ambiente de trabalho.

O projeto de um Home Office é algo bastante específico e individual. Espera-se com essa pesquisa que os indivíduos que obtém pelo trabalho domiciliar fiquem atentos quanto à importância de se manter a saúde do corpo e da mente para que consigam obter sucesso na profissão e que não sofram no decorrer dos anos, as consequências que podem vir a acontecer quando o espaço e os instrumentos de trabalho não são adequados.

\section{REFERÊNCIAS BIBLIOGRÁFICAS}

ASSOCIAÇÃO BRASILEIRA DE ERGONOMIA, ABERGO. O que é ergonomia? Disponível em: <http://www.abergo.org.br/internas.php?pg=o_que_e_ergonomia> Acesso em: 15, jun. 2016. 
AVANCINI, Fabrício; FERREIRA, Flávio. Ergonomia e postura no trabalho. Rio de Janeiro: Editora Virtual Científica, 2003. ISBN: 85-89664-04-X

BRIK, Marina Sell; BRIK, André Sell. Trabalho portátil: produtividade, economia e qualidade de vida no Home Office das empresas. Goiânia: AB-, 2013 ISBN: 8591214919

CASTELLS, Manuel. A Sociedade em Rede. 11. ed. São Paulo: Paz e Terra, 2008. ISBN: 978-85-7657-084-4

COSTA, Isabel de Sá Affonso da. Poder/saber e subjetividade na construção do sentido do teletrabalho. Tese apresentada à Escola Brasileira de Administração Pública e de Empresas como requisito para obtenção de grau de Doutor: FGV, 2003. Disponível em: <http://bibliotecadigital.fgv.br/dspace/bitstream/handle/10438/3273/Capaetc\%202.pdf?seque nce=1> Acesso em: 07 jun. 2016.

DUQUE, Thiago Oliveira. Informática, através da adaptação do diagrama de Corlett, em benefício à saúde ocupacional. Juiz de Fora, MG. Dissertação, Universidade Federal de Juiz de Fora, 2006.

IIDA, Itiro; GUIMARÃES, Lia. Ergonomia: projeto e produção. 3. ed. São Paulo: Blucher, 2016. ISBN: 978-85-212-0933-1

INSTITUTO BRASILEIRO DE GEOGRAFIA E ESTATÍSTICA. Resultados. Disponível em: <http://censo2010.ibge.gov.br/resultados> Acesso em: 07 jun. 2016.

KUMAR, Krishan. Da Sociedade Pós-Industrial à Pós-Moderna: novas teorias sobre o mundo contemporâneo. 2. ed. Rio de Janeiro: Jorge Zahar Editor. 1997. ISBN: 8537805971

LAVILLE, Antoine. Ergonomia. São Paulo: EPU: Editora da Universidade de São Paulo, 1977. ISBN: 85-12-18020-X

NOGUEIRA, Roberto. Elaboração e análise de questionários: uma revisão da literatura básica e a aplicação dos conceitos a um caso real. Rio de Janeiro: UFRJ/COPPEAD, 2012. ISBN 85-7508-038-5

OLIVEIRA, Martha Maria Veras. A ergonomia e o teletrabalho no domicílio. Florianópolis: Dissertação... Universidade Federal de Santa Catarina. ago. 1996. Disponível em: $<$ https://repositorio.ufsc.br/handle/123456789/76935?show=full>. Acesso em: 08 jun. 2016.

PANERO, Julius; MARTIN, Zelnik. Dimensionamento humano para espaços interiores: um livro de consulta e referências para projetos. Barcelona: Editorial Gustavo Gili, 2013. ISBN: 978-84-252-1835-4

PRODANOV, Cleber Cristiano; FREITAS, Ernani Cesar de. Metodologia do trabalho científico: métodos e técnicas da pesquisa e do trabalho acadêmico. 2. ed. Novo Hamburgo, RS: Editora Feevale, 2013. ISBN: 978-85-7717-158-3

RAFALSKY, Julia Carolina; ANDRADE, Alexsandro Luiz de. Home office: aspectos exploratórios do trabalho a partir de casa. Ribeirão Preto: Temas psicol. vol. $23 \mathrm{n}$. 2. jun. 2015. Disponível

em: <http://pepsic.bvsalud.org/scielo.php?script=sci_arttext\&pid=S1413-389X2015000200013>. Acesso em: 08 jun. 2016. ISSN: 1413-389X 
SANTOS, Simone Martins da Cunha. O Home Office como parte da reestruturação do trabalho no capitalismo pós-moderno. Rio de Janeiro: Universidade Candido Mendes. 2012.

SERVIÇO BRASILEIRO DE APOIO À MICRO E PEQUENAS EMPRESAS, SEBRAE. Como montar um home office. Disponível em: <http://www.sebrae.com.br/sites/PortalSebrae/ideias/como-montar-um-homeoffice,c0287a51b9105410VgnVCM1000003b74010aRCRD>. Acesso em: 08 jun. 2016. 